\title{
Prevalence and Factors Influencing Elderly Abuse: A Descriptive Study of Jureli Village, Bakaiya
}

\author{
Keshab Prasad Timalsina \\ Lecturer, Makawanpur Pultiple Campus \\ timalsina.keshab73234@gmail.com
}

Received: March 18, 2021; Revised \& Accepted: March 30, 2021; Published: June 30, 2021

(C) Copyright: Timalsina (2021).

\begin{abstract}
The elderly abuse in a family is one of the most challenging problems in a society. The present study aims to assess the prevalence of elderly abuse in the family environment of JureliTole of Bakaiya Rural Municipality. The study also presents various risk factors that influence the prevalence of Elderly abuse. A descriptive cross-sectional study was carried out among 103 elders taken from household survey by using census method. The data were collected through a face-to-face structured interview schedule. The descriptive and regression analysis of the collected data showed that the prevalence of elderly abuse was $46.6 \%$ in the study population. This study measured significant association $(p<0.05)$ of overall abuse against the elder with only two socio-demographic variables (literacy status and health status) among the variables (gender, age groups, living with or without spouse, literacy status, health status, dependency status, and income level). The results showed that the elders with/without spouse had the highest odds ratio to be abused (2.19 times) followed by gender (1.64 times), and health status (1.25 times). Although this study found lower prevalence than many previous studies, it is still significant and needs to be prevented. Based on the study, it can be said that living without a spouse, with poor health, and being female are the major predictive descriptors for elderly abuse. The policies and programs are needed for the prevention of elderly abuse which may require collective action from social, health and justice sectors.
\end{abstract}

Keywords: Aging, Elderly abuse, Prevalence of Abuse, Influencing Factors, and Psychological Abuse

\section{INTRODUCTION}

Abuse and neglect of the elderly is a significantly widespread social issue within our society today. Tomita (1983) claims elderly abuse is a difficult problem to solve because it generally occurs in the home behind closed doors. Ageing begins with conception and ends with death. Biologically ageing is characterized by diminishing the functions of the body (Arsahad\& Bhat, 2013). WHO defines senior citizens as people 60 years and above. Elderly population is becoming the most challenging demographic phenomenon at global level. On the basis of the 
evidence related to a growing body of research in the area of psychological, social, and health needs of the elderly population, Chalise (2019) claims the issues concerning elder people are regarded as a research priority in most of the developed countries. Kent et al. (2000) states that despite having low attention, there is also considerable need for research in the issue of abuse against elderly people in developing and the least developed countries. As the global ageing population is growing rapidly in the $21^{\text {st }}$ century, elderly people will be larger in numbers in the developing countries.

Mistreatment of older people referred to as elder abuse was first described in British scientific journal in 1975 under the term 'Grandy Battering' (Baker, 1975). Elderly abuse is a serious human rights contravention that requires urgent operation. Silvia (2008) discusses that elder abuse is also a major cause of health problems because it leads to serious health problems, including increased risk of morbidity, mortality and hospital admission. It also has a negative effect on families and society. Understanding the immensity of elder abuse is a crucial first step to prevent this type of violence.

National Human Right Commission and Geriatric Centre Nepal (NHRCGN) carried out a baseline study on reported cases of elder abuse in 2011. Findings of such a survey conducted in Nepal showed the presence of "... physical abuse 43 percent, neglect 33.33 percent and mistreatment leading to death of elderly victims 49 percent of [the total surveyed] cases ..." (NHRCGN, 2011, p. 13 ).

For this study social exchange theory that was developed by George C. Homans in the year 1950 is adopted. This theory explains that social interaction takes place based on an exchange relationship. Mathew and Nair (2017) states that "the major principle of this theory is that the individual in social situations choose behaviors that maximize their likelihood of meeting self-interests in those situations" (p. 31).

Globally, the elderly abuse has been recognized as an issue of research; however, quantitative prevalence studies are rare (Yon et al., 2017). Furthermore, the number of studies on elderly is very low in Nepal. Chalise and Basnet (2017) stated that "Research about the abuse of older persons is also quite new in Nepalese society" (p. 1). GCN (2010) also recommended carrying out a baseline study with multiple indicators to assess the status of elderly. These are the major gaps based on which this study is going to be conducted. Therefore, this study has been carried out to measure the prevalence of abuse against the elders who are living with family in Jureli village of Bakaiya Rural Municipality of Nepal.

\section{OBJECTIVES OF THE STUDY}

- To assess the prevalence of elder abuse in the family environment of Jureli Village.

- To analyze the influencing risk factors of the Elderly abuse.

\section{HYPOTHESIS OF THE STUDY}

- There is a statistical association between the prevalence of abuse and socio-demographic characteristics (Gender, age, spousal living status, literacy, income, health status, and dependency status) of elderly people 
- The socio-demographic factors (Gender, age, spousal living status, literacy, income, health status, and dependency status) can predict elderly abuse.

\section{METHODS AND MATERIALS}

This study was based on cross-sectional descriptive design. It employed quantitative methods of social research where the researcher described the prevalence and risk factors of abuse among the respondents being faced in a family environment during the last 12 months period. This study collected the information about abuse against elders in the family during the last 12 months through structured survey form from which prevalence of elderly abuse was measured, and influencing risk factors associated with elderly abuse was analyzed. This study used a household survey for 67 households of JureliTole of Bakaiya Rural Municipality and information was collected from all the elders that were found at the time of data collection in 67 households. This study gathered data from 103 elders who were found at the time of data collections. So, this study used a census method to include the respondents to meet the objective of the present study. Structured interview schedule with three sections was prepared for the data collection and the data was collected February 29 to March 10, 2020 by the enumerator who was appointed by the researcher after providing training of data collection. And obtained data was analyzed by using descriptive statistics and odds ratio of binary logistic regression for assessing the prevalence rate of elderly abuse and analyzing the influencing risk factors of elderly abuse.

\section{RESULTS}

\section{Socio-demographic Characteristics of Elderly People}

Table 1 shows the socio-demographic characteristics of elderly people. As per the gender perspective, about more than half of elderly people were found male which comprises $52.4 \%$ $(\mathrm{N}=54)$ whereas $47.6 \%(\mathrm{~N}=49)$ were found female. The male elderly people were found more than females. As per the literacy status perspective, the majority of the elderly population was found in the group of illiterate which constituted about $58.3 \%(\mathrm{~N}=60)$, and the remaining $41.7 \%$ $(\mathrm{N}=43)$ was found in the literate group. Similarly, the study has taken age as significant characteristics of elderly people to analyze the prevalence of elderly abuse. Ages are grouped into four categories in the study. As per the age perspective, the majority of elderly people were found in the age group 75 and above. Nearly one-third (30.1\%; \& N=31) elderly people were found in the age group 75 years and above. The second-largest population of the elderly was found in the age group 70-74 years which comprises about one-fourth $(25.2 \%$; \& $\mathrm{N}=26)$ size of the population. Age groups 65-69 years were found as the smallest size of the elderly population among the four groups which accounts for about one-fifth $(20.4 \%$; \& $\mathrm{N}=21)$ size of elderly people. 
Table 1 Socio-economic Characteristics of Elderly People

\begin{tabular}{llll}
\hline Socio-economic Characteristics & Number of Respondents & Percentage \\
\hline Gender & Male & 54 & 52.4 \\
Literacy Status & Female & 49 & 47.6 \\
& Literate & 43 & 41.7 \\
& Illiterate & 60 & 58.3 \\
Age Group & $60-64$ & 25 & 24.4 \\
& $65-69$ & 21 & 20.4 \\
& $70-74$ & 26 & 25.2 \\
Living with/ & $75 \&$ above & 31 & 30.1 \\
without spouse & With spouse & 75 & 72.8 \\
& Without spouse & 28 & 27.2 \\
Health Status & Poor & 9 & 8.7 \\
& Fair & 75 & 72.8 \\
Dependency & Good & 19 & 18.4 \\
Status & Dependent & 51 & 49.5 \\
Income Level & Independent & 52 & 50.5 \\
& Poor & 74 & 71.8 \\
& Medium & 16 & 15.5 \\
& High & 13 & 12.6 \\
\hline
\end{tabular}

$$
\mathrm{N}=103
$$

Similarly, as per the spousal living status perspective, the elderly population was grouped into two categories. More than seven in ten of the elderly population $(72.8 \%, \& \mathrm{~N}=75)$ was found in the category of living with a spouse and the remaining volume of the elderly population $(27.2 \%, \& \mathrm{~N}=28)$ was found in the category of not living with a spouse.

The health status of elderly people also plays a significant role in determining the prevalence of elderly abuse. The above data shows that the majority of the elderly people were found in the category of fair health status. It constituted more than seven in ten of the elderly population $(72.8 \%, \& \mathrm{~N}=75)$. The elderly people having poor health and good health were found to be $8.7 \%(\mathrm{~N}=9)$ and $18.4 \%(19)$ respectively. Similarly, the dependency status of elderly people is directly related to the case of elderly abuse. Further, the income level was another significant factor for analyzing the prevalence of elderly abuse in the study. This study found the largest volume of elders in the low-income group which constituted more than seven in ten of the elderly population $(71.8 \%, \& N=74)$. Similarly, about $15.5 \%$ of the elderly people were found in the group of medium income. And about $12.6 \%$ of the elderly people were found to be high income.

\section{Prevalence of Overall Abuse and Types of Abuse}

One of the focuses of the study was to assess the prevalence and types of elderly abuse in the family environment. Elderly abuse is a prevalent problem across the world. It is important to 
understand that the prevalence of elderly abuse may differ by type. The data presented in Table 2 highlights the frequency distribution of elderly people as per the types of abuse and overall abuse faced and not faced by them during the last 12 months period of study. The distribution of 103 numbers of the elderly population is presented in the table. In the study, the prevalence of abuse was found $46.6 \%(\mathrm{~N}=48)$, and the remaining $53.4 \%(\mathrm{~N}=55)$ elderly population was not subjected to abuse against them. The prevalence of elderly abuse by the types of abuse can be analyzed based on Table 2 . The study found psychological abuse as the most common form of abuse $(26.2 \%, \& \mathrm{~N}=27)$ experienced by elderly people, followed by economic abuse $(22.3 \%$ \& $\mathrm{N}=23)$, neglect $(18.4 \%, \& \mathrm{~N}=19)$, physical abuse $(6.8 \%, \& \mathrm{~N}=7)$ and sexual abuse $(1.9 \%, \&$ $\mathrm{N}=2$ ).

Table 2 Prevalence of Overall Abuse and Types of Abuse

\begin{tabular}{|c|c|c|c|c|}
\hline \multirow[t]{2}{*}{ Overall/Types of Abuse } & \multicolumn{2}{|c|}{ Abused } & \multicolumn{2}{|c|}{ Not Abused } \\
\hline & Count & Percentage & Count & Percentage \\
\hline Overall Abuse & 48 & 46.6 & 55 & 53.4 \\
\hline \multicolumn{5}{|l|}{ Types of Abuse } \\
\hline Neglect & 19 & 18.4 & 84 & 81.6 \\
\hline Psychological & 27 & 26.2 & 76 & 73.8 \\
\hline Economic & 23 & 22.3 & 80 & 77.7 \\
\hline Sexual & 2 & 1.9 & 101 & 98.1 \\
\hline Physical & 7 & 6.8 & 96 & 93.2 \\
\hline
\end{tabular}

\section{Association of prevalence of elderly abuse across socio-demographic characteristics}

This study has taken gender as a significant factor in determining the prevalence of elderly abuse. The study assumed that there is a gender difference in the prevalence of elderly abuse. The data presented in Table 3 highlights the association between the prevalence of abuse and the gender of the elderly population. The study found that the elderly female population was highly subjected to abuse than its counterpart (male). In the case of overall abuse, among the total female population of elders, $53.1 \%$ was subjected to abuse whereas it was only $40.7 \%$ in males. The Association between the prevalence of abuse and gender was found significant because its p-value was estimated to be 0.211 at $95 \%$ level of confidence which is greater than 0.05 with a phi-correlation coefficient value 0.123 . Therefore, the study measured that there is no significant association between the prevalence of overall abuse and the gender of the elderly population. 
Table 3: Prevalence of elderly abuse by socio-economic characteristics

\begin{tabular}{llllll}
\hline Socio-economic Characteristics & Abused & Not Abused & Sig. Value & Statistical Value \\
\hline Gender & Male & $22(40.7 \%)$ & $32(59.3 \%)$ & 0.211 & $0.123^{*}$ \\
& Female & $26(53.1 \%)$ & $23(46.9 \%)$ & & \\
Literacy Status & Literate & $19(35.2 \%)$ & $35(64.8 \%)$ & 0.015 & $0.240^{*}$ \\
& Illiterate & $29(59.2 \%)$ & $20(40.8 \%)$ & & \\
& $60-64$ & $10(40.0 \%)$ & $15(60.0 \%)$ & 0.796 & $1.021^{* *}$ \\
Age Group & $65-69$ & $10(47.6 \%)$ & $11(52.4 \%)$ & & \\
& $70-74$ & $14(53.8 \%)$ & $12(46.2 \%)$ & & \\
\multirow{5}{*}{ Living with/ } & With spouse & $31(41.3)$ & $44(58.7 \%)$ & 0.079 & $0.173 *$ \\
without spouse & Without spouse & $17(60.7 \%)$ & $11(39.3 \%)$ & & \\
& Poor & $7(77.8 \%)$ & $2(22.2 \%)$ & 0.002 & $12.503 * *$ \\
Health Status & Fair & $27(36.0 \%)$ & $48(64.0 \%)$ & & \\
& Good & $14(73.7 \%)$ & $5(26.3 \%)$ & & \multirow{2}{*}{$0.147^{*}$} \\
Dependency & Dependent & $20(39.2 \%)$ & $31(60.8 \%)$ & 0.137 & \\
Status & Independent & $28(53.8 \%)$ & $24(46.2 \%)$ & & $2.091^{* *}$ \\
& Poor & $44(44.6 \%)$ & $41(55.4 \%)$ & 0.351 & \\
Income Level & Medium & $10(62.5 \%)$ & $6(37.5 \%)$ & & \\
& High & $5(38.5 \%)$ & $8(61.5 \%)$ & & \\
\hline
\end{tabular}

$\mathrm{N}=103, *$ Phi correlation coefficient and $* *$ Chi-square value

The frequency distribution presented in the Table 3 shows that nearly three-fifths of the elderly population who was illiterate $(59.2 \%)$ was subjected to abuse whereas such prevalence was found low (35.2\%) among the literate elders. From the above information, the study found differences in the prevalence of overall abuse by literacy rate. Furthermore, table 3 presented the data about the phi-correlation coefficient with its significant value for this case. The study found 0.240 value of the phi-correlation coefficient with $p$-value $<0.05$; which indicates the significant association between the prevalence of overall abuse and the literacy status of elders.

The study found the highest prevalence of abuse (53.8\%) in the age group 70-74 years compared to other age groups of the elderly population taken in the study. The prevalence of overall abuse was found in more than half of the elderly population of age 70-74 years $(55.56 \%)$ followed by $65-69$ years $(47.6 \%), 75$ years and above $(45.2 \%)$, and $60-64$ years $(40.0 \%)$. These data proved that there was an age difference in the prevalence of abuse. The data presented in Table 4 also highlights the value of the chi-square test and the significance at $95 \%$ confidence level. Data shows the insignificant association between the prevalence of overall abuse and the age of the elderly population because its p-value was found to be 0.796 which is greater than 0.05 with 20.62 value of chi-square test. Thus, the study found a significant association between the prevalence of elderly abuse and the age groups of elders. 
The data presented in Table 3 indicates the frequency distribution of prevalence of overall abuse as per spousal living status. Further, it also shows the statistical association between them. The study found that about two-thirds of the elderly population $(60.7 \%)$ living without a spouse was subjected to abusive behaviour in the family whereas such prevalence rate was only $41.3 \%$ in the group of the elders living with a spouse. The study measured 0.173 phicorrelation coefficient at $95 \%$ level of confidence. Moreover, its p-value was found 0.079 which is greater than 0.05 . Therefore, the study concludes that the association of elderly abuse is not statistically significant with spousal living status.

Table 3 shows that the prevalence of overall abuse against elders was highest among elders whose health status was found poor. About more than three-fourths of the population of elders $(77.8 \%)$ having poor health status was subjected to overall abuse in the study which was slightly more than seven in ten (73.7\%) and one-third (36.0\%) among the elders having good and fair health status respectively. The statistical value supported that there is significant association between the prevalence of overall abuse and the health status of elders because its p-value was $<0.05$. The chi-square value measured in the study was 12.50 at $95 \%$ level of confidence. Similarly, the study found about two-fifths of the elderly population (39.2\%) among the dependent group experienced abusive behavior whereas such prevalence rate was higher among independent elders (53.8\%). The study measured 0.147 phi-correlation coefficients of overall abuse at $95 \%$ level of confidence. Moreover, it measured a p-value $>0.05$; indicating that there is an insignificant association between the prevalence of overall abuse against elders and their dependency status.

Table 3 shows that the prevalence of overall abuse against elders was highest among elders whose income level was medium than other levels. About more than three-fifths of the elder population $(62.5 \%)$ having medium-income level was subjected to overall abuse which was about more than two-fifths (44.6\%) and slightly less than two-fifths $(38.5 \%)$ among the elders having low and high-income levels respectively. These data proved that the prevalence of overall abuse differs by income level of elders. The statistical value supported that there is no significant association between the prevalence of overall abuse and the income level of elders because its $\mathrm{p}$ value was $>0.05$ with the chi-square value 50.678 at $95 \%$ level of confidence.

\section{Influencing Risk Factors of Elderly Abuse}

\section{Gender as a Risk Factor}

Table 4 shows that female elders were more likely to have been abused in the last 12 months than the male elders' population in general. The odds ratio of overall abuse tells that the female elder was about 1.64 times more likely to be victims of overall abuse in the study. Furthermore, the odds ratio presented in the above table clarifies that the elder female population was 1.66 times more likely to be victims of neglect, 1.89 times more likely to be victims of psychological or emotional abuse, 1.26 times more likely to be victim of economic abuse and 2.95 times more likely to be victims of physical abuse than the male elders. 
Table 4: Odds ratio of elder abuse by gender

\begin{tabular}{|c|c|c|c|c|c|c|}
\hline Gender & $\begin{array}{l}\text { Odd ratio } \\
\text { Overall abuse }\end{array}$ & Neglect & $\begin{array}{l}\text { Psychological } \\
\text { abuse }\end{array}$ & $\begin{array}{l}\text { Economic } \\
\text { abuse }\end{array}$ & $\begin{array}{l}\text { Sexual } \\
\text { abuse }\end{array}$ & Physical abuse \\
\hline Male/Female & $1.644 * *$ & $1.664 * *$ & $1.895 * *$ & $1.268 * *$ & $0.945 * *$ & $2.955 * *$ \\
\hline $\begin{array}{r}\text { Reference cat } \\
\text { Age as a Risk } \\
\text { Table } \\
\text { the last } 12 \mathrm{mc} \\
\text { study found tl } \\
\text { more likely to } \\
\text { risk of neglec } \\
\text { years and abo } \\
\text { risk of having } \\
\text { times more lil }\end{array}$ & $\begin{array}{l}\text { egory= Male, Bi } \\
\text { Factor } \\
5 \text { shows that eld } \\
\text { nths than the be } \\
\text { lat the elders of } \\
\text { be victims of o } \\
\text { for various age } \\
\text { ve age group. Fo } \\
\text { abuse for both } \\
\text { ely to be victim }\end{array}$ & $\begin{array}{l}\text { ary Logis } \\
\text { ers having } \\
\text { inning pe } \\
5-69 \text { year } \\
\text { erall abus } \\
\text { groups wa } \\
5-69 \text { and } 7 \\
75 \text { and at }\end{array}$ & $\begin{array}{l}\text { tic Regression c } \\
\text { a higher age we } \\
\text { iod of old age ( } \\
\text { s age group wer } \\
\text { than the elders } \\
\text { s found } 2.56 \text { tim } \\
\text { of economic abu } \\
0-74 \text { years of ag } \\
\text { ove years. }\end{array}$ & $\begin{array}{l}\text { oefficient } * \mathrm{p} \\
0 \text {-64 years) } \\
1.36 \text { times, } \\
\text { belonging to } \\
\text { es for } 70-74 \\
\text { se, the study } \\
\text { e, but it was }\end{array}$ & $\begin{array}{l}<0.05 * * \mathrm{p}- \\
y \text { to have b } \\
\text { population } \\
70-74 \text { year } \\
\text { the age gr } \\
\text { years and } \\
\text { estimated } \\
\text { found abc }\end{array}$ & $\begin{array}{l}0.05 \\
\text { een abused in } \\
\text { in general. The } \\
\text { s was } 1.87 \text { times } \\
\text { oup } 60-64 \text {. The } \\
2.44 \text { times for } 75 \\
3.66 \text { times more } \\
\text { ut only } 1.22\end{array}$ \\
\hline
\end{tabular}

Odd ratio

Age Group Abuse (All) Neglect Psychological abuse Economic Sexual Physical abuse

\begin{tabular}{|c|c|c|c|c|c|c|}
\hline & & & & abuse & abus & \\
\hline $65-69$ years & $1.364 * *$ & $0.772 * *$ & $0.250 * *$ & $3.667 * *$ & NA & $1.211 * *$ \\
\hline $70-74$ years & $1.875^{* *}$ & $2.567 * *$ & $0.750 * *$ & $3.667 * *$ & NA & $0.920 * *$ \\
\hline $75 \&$ above & $0.971 *$ & $2.444 * *$ & $0.180^{*}$ & $1.222 * *$ & NA & $0.426^{* *}$ \\
\hline
\end{tabular}

Reference category $=60-64$ years, Binary Logistic Regression coefficient $* \mathrm{p}<0.05 * *>0.05$ and $\mathrm{NA}=$ Not applicable

\section{Living with or without Spouse as a Risk Factor}

The data presented in Table 6 shows the older people living without a spouse were at a greater likelihood of being abused in the last 12 months compared to those living with a spouse. Table 6 shows that elders living without a spouse were 2.19 times more likely to be victims of overall abuse in the study. In particular, older people living without a spouse were about 1.75 times more likely to be victims of neglect than older people living with a spouse. Similarly, such probabilities were 1.50 times, 2.06 times, and 4 times more likely to be victims of psychological/emotional abuse, economic abuse, and physical abuse respectively. The study concludes that the elders living without a spouse are at a greater likelihood of being abused compared with those living with a spouse. 
Table 6: Odds ratio of elderly abuse by living with/without spouse

Odd ratio

\begin{tabular}{|c|c|c|c|}
\hline atus & Overal & Neglect & Psychologica \\
\hline
\end{tabular}

\begin{tabular}{lllllll}
\hline Without / with & $2.194 * *$ & $1,750 * *$ & $1.504^{* *}$ & $2.064 * *$ & NA & $4.00 * *$
\end{tabular}
spouse

Reference category= living with spouse, Binary Logistic Regression coefficient $* \mathrm{p}<0.05$ $* *>0.05$ and $\mathrm{NA}=$ Not applicable

\section{Literacy status as a Risk Factor}

Table 7 shows that illiterate elders were more likely to have been abused in the last 12 months than the literate elders' population in general. The study found that illiterate elders were $27 \%$ less likely to be victims of overall abuse. In particular, illiterate elders were 4.85 times more likely to be victims of neglect, 6.06 times as likely to be victims of psychological/emotional abuse, $64 \%$ less likely to be victims of economic abuse, and $86 \%$ more likely to be victims of physical abuse than literate elders in the study.

Table 7: Odds ratio of elderly abuse by literacy status

$$
\text { Odd ratio }
$$

Literacy status Overall abuse Neglect Psychological Economic Sexual Physical abuse Abuse abuse abuse

\begin{tabular}{lllllll}
\hline Literate/ & $0.730^{* *}$ & $4.848^{*}$ & $6.061^{*}$ & $0.366^{*}$ & NA & $1.864 * *$
\end{tabular}

Illiterate

Reference category= literate, Binary Logistic Regression coefficient $* p<0.05$

$\mathrm{NA}=$ Not applicable

\section{Health status as a Risk Factor}

The study found that the older people having fair health status were at a greater likelihood of being abused in many cases and such likelihood was further greater among older people having poor health compared with those having good health status. This study found about twice and $80 \%$ less and $25 \%$ more likely to be victims of overall abuse among elders whose health status were fair and poor respectively compared with elders having good health status. In the case of neglect, the probability of being abused was 3.77 and 22.5 times more respectively among the same groups of elders and it was about $53 \%$ less and $37 \%$ more in the case of psychological/emotional abuse among the same group of elders as analysed in overall abuse. And as per the physical abuse, likelihood of abuse was measured $85 \%$ less and 52\% more among the elders having fair and poor health status respectively. 
Table 8: Odds ratio of elderly abuse by health status

\begin{tabular}{lllllll}
\hline $\begin{array}{l}\text { Health } \\
\text { Status }\end{array}$ & $\begin{array}{l}\text { Odd ratio } \\
\text { Abuse }\end{array}$ & Neglect & $\begin{array}{l}\text { Psychological } \\
\text { abuse }\end{array}$ & $\begin{array}{l}\text { Economic } \\
\text { abuse }\end{array}$ & $\begin{array}{l}\text { Sexual } \\
\text { abuse }\end{array}$ & $\begin{array}{l}\text { Physical } \\
\text { abuse }\end{array}$ \\
\hline Poor & $1.250^{* *}$ & $22.50^{*}$ & $1.371^{* *}$ & $0.450^{* *}$ & NA & $\mathbf{1 . 5 2 4 * *}$ \\
Fair & $0.201^{*}$ & $3.774^{* *}$ & $0.465^{* *}$ & $0.138^{*}$ & NA & $\mathbf{0 . 1 4 6 *}$ \\
\hline
\end{tabular}

Reference category $=$ Good health, Binary Logistic Regression coefficient $* p<0.05 * *>0.05$ and $\mathrm{NA}=$ Not applicable

\section{Income Level as Risk Factor}

The study 0bserved the older people having medium income status were at a greater likelihood of being abused in many cases compared with those having a high level of income. The study found that the elders who had medium and low-income levels were about equal and $15 \%$ less likely to be victims respectively from overall abuse compared with elders having a high-income level. In particular, such likelihoods were 2.14 and 1.78, and 3.33 and 1.44 times more in psychological/emotional abuse and economic abuse respectively among the elders having medium and low-income level. Therefore, the study concludes that the probability of abuse against the elders increases with decreasing the level of income.

Table 9: Odds ratio of elderly abuse by income level

\begin{tabular}{lllllll}
\hline $\begin{array}{l}\text { Income } \\
\text { level }\end{array}$ & $\begin{array}{l}\text { Odd ratio } \\
\text { Overall }\end{array}$ & Neglect & $\begin{array}{l}\text { Psychological } \\
\text { abuse }\end{array}$ & $\begin{array}{l}\text { Economic } \\
\text { abuse }\end{array}$ & $\begin{array}{l}\text { Sexual } \\
\text { abuse }\end{array}$ & $\begin{array}{l}\text { Physical } \\
\text { abuse }\end{array}$ \\
\hline Low & $0.854^{* *}$ & $1.230^{* *}$ & $1.786^{* *}$ & $1.441^{* *}$ & NA & NA \\
Medium & $1.00^{* *}$ & $0.000^{* *}$ & $2.143^{* *}$ & $3.333^{* *}$ & $1.00^{* *}$ & $1.00^{* *}$ \\
\hline
\end{tabular}

Reference category $=$ High income level, Binary Logistic Regression coefficient $* \mathrm{p}<0.05$ $* *>0.05$ and $\mathrm{NA}=$ Not applicable

\section{Dependency status}

The data presented in Table 10 highlights the odds ratio of cases of abuse by the dependent and independent status of elders and found quite opposite results than usual for the study area. In the study, dependency status was not observed as a relevant risk factor for the case of abuse against elders. Table 10 shows that dependent elders were less likely to have been abused in the last 12 months than independent elders. The odds ratio of overall abuse reveals that dependent elders were about $45 \%$ less likely to be victims of overall abuse in the study. In particular, the study found dependent elders were $10 \%, 68 \%, 42 \%$, and $62 \%$ less likely to be victims of neglect, psychological/emotional abuse, economic abuse, and physical abuse 
respectively and about equal likelihood of being abused was observed for the case of sexual abuse between independent and dependent elders who were studied in this research.

Table 10: Odds ratio of elderly abuse by dependency status

\begin{tabular}{lllllll}
\hline Dependency status & \multicolumn{2}{l}{ Odd ratio } & & & & \\
& $\begin{array}{l}\text { Abuse } \\
\text { all }\end{array}$ & Neglect & $\begin{array}{l}\text { Psychological } \\
\text { abuse }\end{array}$ & $\begin{array}{l}\text { Economic } \\
\text { abuse }\end{array}$ & $\begin{array}{l}\text { Sexual } \\
\text { abuse }\end{array}$ & Physical abuse \\
\hline $\begin{array}{l}\text { Dependent/ } \\
\text { Independent }\end{array}$ & $0.553^{* *}$ & $0.900^{* *}$ & $0.323^{*}$ & $0.582^{* *}$ & $1.020^{* *}$ & $0.384^{* *}$ \\
\hline
\end{tabular}

Reference categories $=$ Independence, Binary Logistic Regression coefficient $* \mathrm{p}<0.05 * *>0.05$ and NA= Not applicable

\section{DISCUSSION}

This study assesses the prevalence of elderly abuse in the family environment and further it aimed to analyze influencing risk factors associated with elderly abuse. This study found nearly half (46.6\%) of elderly people were subjected to overall abuse during the last 12 months period. The overall prevalence pf elderly abuse of this finding $(46.6 \%)$ is less than the previous study of Yadav and Paudel (2016) for Butwal, Nepal (49.1\%) and very close with Chalise and Basnet (2017) for developing countries (47.4\%), and higher than the study of Bista and Joshi (2015) for Kathmandu Nepal (26\%). A similar study conducted in the eastern part of Nepal estimated a $47.4 \%$ prevalence rate of overall abuse which is also very close to the present finding (Chalise\& Basnet, 2017). Regarding different types of abuse, the most common form of abuse found in the study was psychological/emotional abuse which accounts one-third $(26.2 \%)$ of the study population, followed by economic abuse (22.3\%), neglect (18.4\%), physical abuse (6.8\%) and sexual abuse (1.9\%). Furthermore, this study measured significant association between literacy status and elderly abuse and such association was also measured significantly with health status of elderly people but with the remaining socio-demographic variables the association was observed insignificant. Unlike the previous study, this study observed insignificant influencing risk factors for causing elderly abuse with all socio-demographic characteristics that are taken in this study (WHO, 2014 \&Awal et al. 2020).

\section{CONCLUSION}

The prevalence of elderly abuse measured by this study is high. The study identified the significant relation between the elder abuse and twosocio-demographic characteristics of eldersnamely; literacy status and health status but it observed insignificant association with remaining characteristics of the elders (variables). Similarly, the study observed some of the socio-demographic variables taken in the study like; literacy status, living with/without spouse and health status are significant influencing risk factors for causing elderly abuse. This study has 
provided the data about the Odds ratio of elderly abuse by various socio-demographic variables taken in the study can be usable to identify the elders who are at high risk of abuse and protect them by taking multi-sectoral action for social justice.

\section{REFERENCES}

Arshad, M., \& Bhat, S. A. (2013). Global ageing trends: A sociological perspective. Int J Curr Res Acad Rev 1, 55-64.

Awal, M. R., Majumder, U. K., \&Haque, M. M. (2020). Factors Associated with Abuse and Neglect of the Elderly Peoples of Chitmahal Areas in Bangladesh. Asian Journal of Education and Social Studies, 8(1), 34-50.

Baker, P. R., Francis, D. P., Hairi, N. N., Othman, S., \& Choo, W. Y. (2016). Interventions for preventing abuse in the elderly. Cochrane Database of Systematic Reviews.

Bista, A., \& Joshi, S. (2015). Health problems of elderly residing in urban areas, Kathmandu. Journal of Institute of Medicine, 37(2), 56-61

Chalise, H. N., \& Basnet, M. (2017). Abuse of Older Adults Residing in the Community of Nepal. Journal of Gerontology \& Geriatric Research, 6(2).

Chalise, H. N.(2017). Abuse of the Elderly: A Neglected Issue in Developing Countries . $J$ JGeronto, 3(1), 1-5

Chalise, H. N., \&Paudel, B.R. (2020). Elderly Abuse among Community-Living Older Adults of Least Developed Country-Nepal. Arch PhysRehabil Med, 1(1), 1-8.

Geriatric Center Nepal (GCN). (2010). Status Report on Elderly People (60+) in Nepal on Health, Nutrition and Social Status. Government of Nepal Ministry of Health and Population Ramshahpath, Kathmandu.

Khan, Z. R. (2019). Elderly in India: Facts and Issues. Research \& Development, 4(8), 60-64.

Mathew, A., \& Nair, S. B. (2017). Theoretical Perspectives on Elder Abuse: A Framework Analysis for Abused Elderly in Kerala.JournalOf Humanities And Social Science, 22(9), 29-33.

National Human Rights Commission Nepal and Geriatiric Center Nepal (NHRCGN). (2011). A Baseline Study on Reported Cases of Elder Abuse in Nepali Press.

Silvia, P.L. (2008). Discussing screening for elder abuse at primary health care level. World Health Organization.

Tomita, S. K. (1983). Detection and Treatment of Elderly Abuse and Neglect:: A Protocol for Health Care Professionals. Physical \& Occupational Therapy In Geriatrics, 2(2), $37-$ 51

World Health Organisation, (WHO). (2014). Ageing Well Must Be a Global Priority. World Health Organisation.

Yadav, U. N., \&Paudel, G. (2016). Prevalence and associated factors of elder mistreatment : a cross sectional study from urban Nepal. Age and Ageing, 45(5),609-613. 